\title{
Endogenous GLP-1 mediates postprandial reductions in activation in central reward and satiety areas in patients with type 2 diabetes
}

\author{
Jennifer S. ten Kulve ${ }^{1}$. Dick J. Veltman ${ }^{2} \cdot$ Liselotte van Bloemendaal $^{1}$ • \\ Frederik Barkhof ${ }^{3} \cdot$ Carolyn F. Deacon $^{4}$ - Jens J. Holst ${ }^{4}$ - Robert J. Konrad ${ }^{5}$. \\ John H. Sloan ${ }^{5} \cdot$ Madeleine L. Drent $^{6,7} \cdot$ Michaela Diamant $^{1} \cdot$ Richard G. IJzerman $^{1}$
}

Received: 3 July 2015 / Accepted: 20 August 2015 / Published online: 18 September 2015

(C) The Author(s) 2015. This article is published with open access at Springerlink.com

\begin{abstract}
Aims/hypothesis The central nervous system (CNS) is a major player in the regulation of food intake. The gut hormone glucagon-like peptide-1 (GLP-1) has been proposed to have an important role in this regulation by relaying information about nutritional status to the CNS. We hypothesised that endogenous GLP-1 has effects on CNS reward and satiety circuits.

Methods This was a randomised, crossover, placebocontrolled intervention study, performed in a university medical centre in the Netherlands. We included patients with type
\end{abstract}

Michaela Diamant, who designed and supervised this research, died on 9 April 2014 before publication of this work.

Jennifer S. ten Kulve

js.tenkulve@vumc.nl

1 Department of Internal Medicine, Diabetes Center, VU University Medical Center, de Boelelaan 1117, 1081

HV Amsterdam, the Netherlands

2 Department of Psychiatry, VU University Medical Center, Amsterdam, the Netherlands

3 Department of Radiology and Nuclear Medicine, VU University Medical Center, Amsterdam, the Netherlands

4 The NNF Center for Basic Metabolic Research, Department of Biomedical Sciences, Panum Institute, University of Copenhagen, Copenhagen, Denmark

5 Lilly Research Laboratories, Eli Lilly and Company, Indianapolis, IN, USA

6 Department of Internal Medicine/Endocrine Section, VU University Medical Center, Amsterdam, the Netherlands

7 Department of Clinical Neuropsychology, VU University, Amsterdam, the Netherlands
2 diabetes and healthy lean control subjects. Individuals were eligible if they were 40-65 years. Inclusion criteria for the healthy lean individuals included a BMI $<25 \mathrm{~kg} / \mathrm{m}^{2}$ and normoglycaemia. Inclusion criteria for the patients with type 2 diabetes included BMI $>26 \mathrm{~kg} / \mathrm{m}^{2}, \mathrm{HbA}_{1 \mathrm{c}}$ levels between 42 and $69 \mathrm{mmol} / \mathrm{mol}(6.0-8.5 \%)$ and treatment for diabetes with only oral glucose-lowering agents. We assessed CNS activation, defined as blood oxygen level dependent (BOLD) signal, in response to food pictures in obese patients with type 2 diabetes $(n=20)$ and healthy lean individuals $(n=20)$ using functional magnetic resonance imaging (fMRI). fMRI was performed in the fasted state and after meal intake on two occasions, once during infusion of the GLP-1 receptor antagonist exendin 9-39, which was administered to block actions of endogenous GLP-1, and on the other occasion during saline (placebo) infusion. Participants were blinded for the type of infusion. The order of infusion was determined by block randomisation. The primary outcome was the difference in BOLD signal, i.e. in CNS activation, in predefined regions in the CNS in response to viewing food pictures.

Results All patients were included in the analyses. Patients with type 2 diabetes showed increased CNS activation in CNS areas involved in the regulation of feeding (insula, amygdala and orbitofrontal cortex) in response to food pictures compared with lean individuals $(p \leq 0.04)$. Meal intake reduced activation in the insula in response to food pictures in both groups $(p \leq 0.05)$, but this was more pronounced in patients with type 2 diabetes. Blocking actions of endogenous GLP-1 significantly prevented meal-induced reductions in bilateral insula activation in response to food pictures in patients with type 2 diabetes $(p \leq 0.03)$.

Conclusions/interpretation Our findings support the hypothesis that endogenous GLP-1 is involved in postprandial satiating effects in the CNS of obese patients with type 2 diabetes. 
Trial registration: ClinicalTrials.gov NCT 01363609

Funding The study was funded in part by a grant from Novo Nordisk.

Keywords fMRI · Food intake - GLP-1 · Neuroimaging · Obesity · Type 2 diabetes

$\begin{array}{ll}\text { Abbreviations } \\ \text { BOLD } & \text { Blood oxygen level dependent } \\ \text { CNS } & \text { Central nervous system } \\ \text { fMRI } & \text { Functional magnetic resonance imaging } \\ \text { GLP-1 } & \text { Glucagon-like peptide-1 } \\ \text { GLP-1RA } & \text { Glucagon-like peptide-1 receptor agonist } \\ \text { OFC } & \text { Orbitofrontal cortex } \\ \text { ROI } & \text { Region of interest }\end{array}$

\section{Introduction}

The role of the central nervous system (CNS) in the regulation of energy balance involves a complex interaction of signals originating from the periphery (i.e. hormones and neuronal signals) and responses of brain areas involved in the reward and regulation of food intake [1]. An excess of food intake compared with energy expenditure induces a chronically positive energy balance causing weight gain and obesity. In the search for strategies to treat and prevent obesity, it is important to increase understanding of the central regulation of feeding and the physiological signals influencing this regulation.

Hormones derived from the gut appear to relay mealrelated information on nutritional status to the CNS, thereby affecting feeding [2]. The gut hormone glucagon-like peptide-1 (GLP-1) is released by enteroendocrine L cells into the circulation following food ingestion. GLP-1 is known for its incretin effect, as it augments meal-related insulin secretion from the pancreas [3]. In addition, results from preclinical and clinical studies demonstrate that administration of GLP-1 or GLP-1 receptor agonists (GLP-1RA) in pharmacological amounts reduces appetite, food intake and body weight [4-8]. In animal studies, the pharmacological effects of GLP-1RA are at least partly mediated through the CNS [9-15]. Results from studies in rodents and humans demonstrate that endogenous GLP-1 (i.e. at lower levels of GLP-1 compared with pharmacological administration of GLP-1RA) plays a role in the regulation of food intake $[16,17]$. Although studies in rodents indicate that this effect is also mediated via the CNS $[11,18]$, the involvement of endogenous GLP-1 in the central regulation of food intake in humans has not been investigated.
Neuroimaging techniques enable non-invasive investigation of the CNS in humans. Functional magnetic resonance imaging (fMRI) can be used to measure food-cue related changes in activity in the CNS. Obese individuals show increased activation when viewing food pictures [19] and in particular pictures of high-energy food [20, 21]. In addition, it was shown that food intake reduces CNS activation in response to viewing food pictures [22]. Furthermore, we recently demonstrated that acute administration of pharmacological amounts of a GLP-1RA diminishes activation to food pictures in areas involved in the regulation of food intake [19].

In the present study, we used fMRI to assess the physiological role of GLP-1 in the central regulation of food intake in obese patients with type 2 diabetes and healthy lean individuals. We measured CNS activation in response to viewing food pictures before and after intake of a meal on two test visits. During one of the visits, the GLP-1 receptor antagonist exendin 9-39 was administered to evaluate the effects of endogenous GLP-1. We hypothesised that the satiating effects of meal intake on CNS activation would be prevented by blocking endogenous GLP-1.

\section{Methods}

Participants The study was approved by the Medical Ethics Review Committee of the VU University Medical Center (VUMC) and conducted in accordance with the Declaration of Helsinki. All participants provided written informed consent. The study included 20 overweight and obese patients with type 2 diabetes and 20 healthy lean individuals matched for sex and age. Individuals were eligible if they were 40-65 years of age and right-handed. Inclusion criteria for the healthy lean individuals included a BMI $<25 \mathrm{~kg} / \mathrm{m}^{2}$ and normoglycaemia, defined by fasting plasma glucose $<5.6 \mathrm{mmol} / \mathrm{l}$ and $2 \mathrm{~h}$ glucose $<7.8 \mathrm{mmol} / \mathrm{l}$ following a $75 \mathrm{~g}$ oral glucose tolerance test. Inclusion criteria for the patients with type 2 diabetes included BMI $>26 \mathrm{~kg} / \mathrm{m}^{2}, \mathrm{HbA}_{1 \mathrm{c}}$ levels between 42 and $69 \mathrm{mmol} / \mathrm{mol}$ $(6.0-8.5 \%)$ and treatment for diabetes of the oral glucoselowering agents metformin \pm sulfonylurea. Exclusion criteria were a history of neurological, cardiovascular, renal or liver disease, malignancies, the use of any centrally acting agent, substance abuse and psychiatric disorders. All patients with diabetes were treated with metformin and 12 patients were also treated with sulfonylurea, but sulfonylurea were temporarily discontinued 4 weeks prior to the start of the experiments. Ten patients used antihypertensive medication and 15 patients used cholesterol-lowering agents.

General experimental protocol This was a placebocontrolled, crossover, acute intervention study. The study 
consisted of two separate test visits. On each visit, two fMRI scans were performed; one while the individual fasted and one at $30 \mathrm{~min}$ after intake of a standardised liquid meal consisting of $1,883 \mathrm{~kJ}$ (carbohydrate $56.1 \mathrm{~g}$, fat $17.4 \mathrm{~g}$ and protein $18.0 \mathrm{~g}$, $300 \mathrm{ml}$ Nutridrink yoghurt style, Nutricia, Zoetermeer, the Netherlands). At each visit, a catheter was inserted into a cubital vein for infusion of, in random order, either placebo (sodium chloride $0.9 \% \mathrm{wt} / \mathrm{vol}$.) or the selective GLP-1 receptor antagonist exendin 9-39 (600 pmol kg ${ }^{-1} \mathrm{~min}^{-1}$; Clinalfa, Bachem, Bubendorf, Switzerland, used to block the effects of endogenous GLP-1), using a MRI-compatible infusion pump (MRIdium 3850 MRI-IV pump, Iradimed, Winter Park, FL, USA). The order of infusion was determined by block randomisation. Each infusion was started $1 \mathrm{~h}$ before the beginning of the MRI scan and was continued during the whole period of scanning. The participants were blinded for the type of infusion. Blood was drawn at fixed intervals to measure glucose, GLP-1, insulin and glucagon levels (Fig. 1a).

fMRI paradigm The fMRI task has been described previously [19]. Briefly, the fMRI task consisted of pictures selected from three different categories: (1) high-energy food items; (2) low-energy food items; (3) non-food items. The pictures were presented via the software E-prime 1.2 (Psychology Software Tools, Pittsburgh, PA, USA). Forty-two pictures per category were presented in a block design (Fig. 1b). The order of the blocks was randomised. Given that each participant was scanned four times, four versions of this paradigm were created with different pictures, with the images being matched between the versions and between the categories for type, shape and colour.
MRI acquisition and analyses Comparable MRI acquisition and analyses were used as described previously [19]. In brief, MRI data were acquired on a 3.0 Tesla GE Signa HDxt scanner (General Electric, Milwaukee, WI, USA) and fMRI data were acquired using an echo planar imaging $\mathrm{T} 2 *$ blood oxygen level dependent (BOLD) pulse-sequence. Functional images were analysed with SPM8 software (Wellcome Trust Centre for Neuroimaging, London, UK). At the first level, high-energy food, low-energy food and non-food blocks were modelled. Next, we computed two contrasts of interest: all food pictures $>$ non-food pictures; high-energy food pictures $>$ non-food pictures. These firstlevel contrast images were entered into second-level threeway ANOVA with factors group (healthy lean, diabetes), infusion (placebo, exendin 9-39) and meal state (fasted, postprandial). A priori regions of interest (ROIs) were determined based on previous studies (i.e. left and right insula, caudate nucleus, putamen, amygdala and orbitofrontal cortex (OFC)) [19-21]. CNS activations are reported as significant when they survive family-wise error correction for multiple comparisons on the voxel level using small volume correction within predefined ROIs, as described previously [19].

Blood sampling and assays Measurement of blood glucose was performed using the glucose dehydrogenase method (GlucoseAnalyser, HemoCue, Ängelholm, Sweden). Total GLP-1 was analysed using a C-terminally directed radioimmunoassay for amidated GLP-1 (antibody 89390) [23]. Insulin levels were measured using an immunometric assay (Advia Centaur, Siemens Medical Solutions Diagnostics, Tarrytown, NY, USA). Glucagon levels were determined using an immunoassay as described previously (Lilly Research Laboratories, Indianapolis, IN, USA) [24].

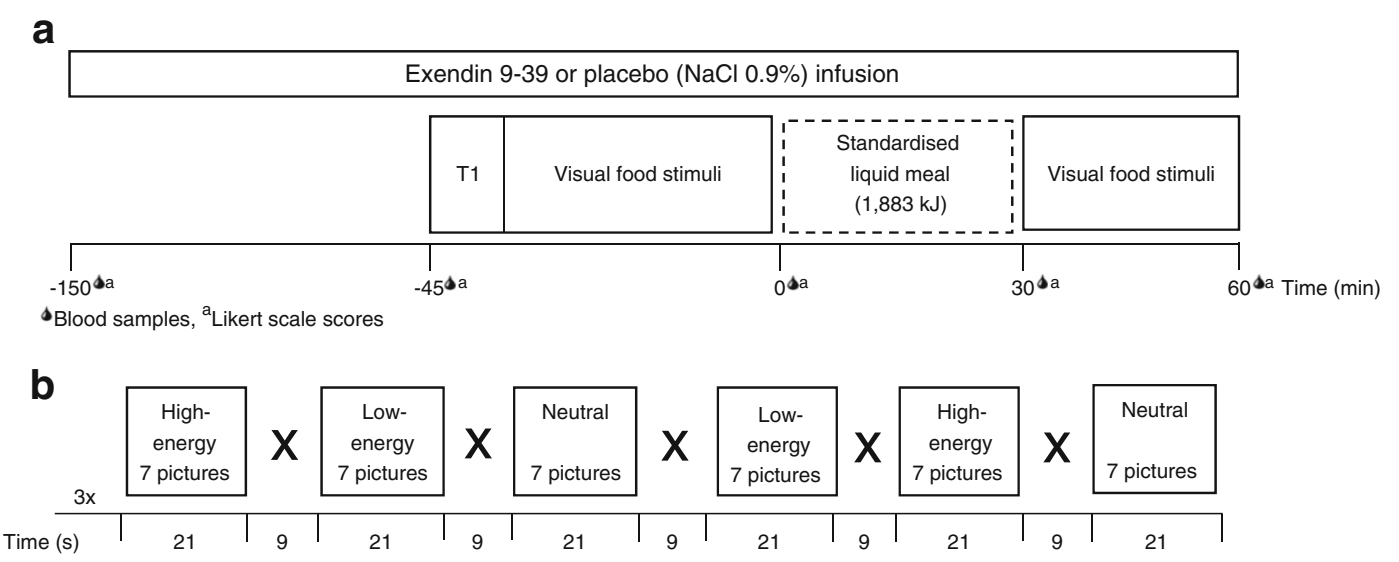

Fig. 1 Study protocol. (a) Study design. Obese patients with type 2 diabetes and healthy lean individuals were studied in a placebo-controlled acute intervention study. The study consisted of two visits (random order): one with a GLP-1 receptor antagonist (exendin 9-39) infusion and one with a saline (placebo) infusion. Infusions started $1 \mathrm{~h}$ before the scan and lasted until the end of the visit. During each visit, two fMRI scans were performed: one while fasted and one $30 \mathrm{~min}$ after the meal

intake. During fMRI, visual-food cues were presented. Blood samples and appetite-related scores on a 10-point Likert scale were taken at fixed time points. T1, structural MRI, T1-weighted sequence. (b) fMRI paradigm. One run comprised six blocks of $21 \mathrm{~s}$ each (seven pictures). Within one run, two blocks of each category were presented. Each MRI session included three runs 
Questionnaires The participants were asked to score their sensations of hunger, fullness, prospective food consumption and nausea on a 10-point Likert scale at four fixed time points during the visits: (1) before the start of the first (fasted) MRI session; (2) before intake of the meal; (3) 30 min after meal intake; (4) 60 min after meal intake. Changes in scores from before meal intake to 30 and $60 \mathrm{~min}$ after intake were analysed and compared between infusions.

Statistical analyses Clinical group data were analysed with the Statistical Package for the Social Sciences version 20 (IBM SPSS Statistics for Windows, Version 20.0. Armonk, NY, USA). Data are expressed as mean \pm SEM (unless otherwise stated). Between-group differences were analysed with independent Student's $t$ test. In cases of measurements with more than one time point on each visit, repeated measures ANOVA was used with time (min) as the within-subject factor and group as the between-subject factor, or treatment as the within-subject factor. Results were considered statistically significant when $p<0.05$.

\section{Results}

Baseline characteristics Table 1 summarises the baseline characteristics of both groups. All participants completed all visits. Due to a technical failure, one postprandial scan of a patient with diabetes during the visit with exendin 9-39 infusion could not be used in the analysis.
The effects of group, meal intake and GLP-1 receptor blockade on CNS activation are presented in Table 2.

Increased CNS activation in response to viewing food pictures in obese patients with type 2 diabetes vs healthy lean individuals During the session with placebo infusion in the fasted condition, obese patients with type 2 diabetes showed increased activation in the right OFC $(p=0.004)$, left amygdala $(p=0.02)$ and bilateral insula (right $p=0.02$ and left $p=0.04$, respectively) in response to food pictures (Fig. 2) and in the right OFC $(p=0.05)$ and left insula $(p=0.04)$ in response to high-energy food pictures. However, in the postprandial condition, increased activation in patients with diabetes was no longer observed in any brain area studied. In addition, we did not observe increased activation in healthy lean individuals compared with patients with diabetes in any of the ROIs either in the fasted or in the postprandial condition.

Meal intake reduced CNS activation in response to food pictures During placebo infusion, both groups showed reduced CNS activation in response to food pictures in the postprandial condition compared with the fasted condition. In healthy lean individuals, this effect of meal intake was observed in the right insula in response to food pictures ( $p=0.02$; Fig. 3a). In addition, meal intake tended to reduce activation in the right insula in response to the high-energy food pictures in lean healthy individuals $(p=0.08)$. In obese patients with type 2 diabetes, CNS activation was also reduced after meal intake in the bilateral insula in response to viewing food pictures (right $p=0.04$, left $p=0.05$; Fig. $3 \mathrm{~b}$ )

Table 1 Baseline characteristics

\begin{tabular}{llll}
\hline Characteristic & Healthy controls $(n=20)$ & Obese T2DM patients $(n=20)$ & $p$ value \\
\hline Age (years) & $56.3 \pm 1.4$ & $59.5 \pm 0.9$ & 0.06 \\
Sex, male/female $(n)$ & $10 / 10$ & $11 / 9$ & 0.8 \\
Weight $(\mathrm{kg})$ & $69.9 \pm 2.5$ & $95.4 \pm 3.4$ & $<0.001$ \\
BMI $\left(\mathrm{kg} / \mathrm{m}^{2}\right)$ & $22.5 \pm 0.4$ & $32.0 \pm 1.1$ & $<0.001$ \\
Waist circumference $(\mathrm{cm})$ & $81.4 \pm 1.8$ & $108.9 \pm 2.5$ & $<0.001$ \\
Body fat $(\%)$ & $24.7 \pm 1.3$ & $38.6 \pm 1.8$ & $<0.001$ \\
Systolic BP $(\mathrm{mmHg})$ & $113 \pm 3.5$ & $128 \pm 2.0$ & 0.001 \\
Diastolic BP (mmHg) & $72.9 \pm 2.5$ & $78 \pm 1.8$ & 0.1 \\
HbA ${ }_{1 \mathrm{c}}(\mathrm{mmol} / \mathrm{mol})$ & $37 \pm 0.4$ & $56 \pm 2.2$ & $<0.001$ \\
HbA 1 (\%) & $5.5 \pm 0.03$ & $7.3 \pm 0.2$ & $<0.001$ \\
Fasting plasma glucose (mmol/l) & $5.2 \pm 0.1$ & $8.4 \pm 0.3$ & $<0.001$ \\
Total cholesterol (mmol/l) & $5.2 \pm 0.2$ & $4.5 \pm 0.3$ & 0.07 \\
Triacylglycerol (mmol/l) & $0.8 \pm 0.1$ & $1.6 \pm 0.1$ & $<0.001$ \\
Diabetes duration (years) & - & $7.8 \pm 1.1$ & - \\
BP-lowering medications $(n)$ & 0 & 10 & $<0.001$ \\
Cholesterol-lowering medications $(n)$ & 0 & 15 & $<0.001$ \\
\hline
\end{tabular}

Data are means \pm SEM or number of individuals $(n)$

T2DM, type 2 diabetes 
Table 2 Effects of group, meal intake and GLP-1 receptor blockade on CNS activation in response to viewing of food pictures and high-energy food pictures

\begin{tabular}{|c|c|c|c|c|c|c|c|}
\hline Contrast used & Comparison & Region & Side & Cluster & $Z$ & FWE $p$ value & $\begin{array}{l}\text { MNI coordinates } \\
(\mathrm{x}, \mathrm{y}, \mathrm{z})\end{array}$ \\
\hline \multicolumn{8}{|l|}{ Group differences } \\
\hline Food $>$ non-food & Healthy controls > T2DM (fasted, placebo) & - & - & - & - & - & - \\
\hline High-energy $>$ non-food & & - & - & - & - & - & - \\
\hline \multirow[t]{4}{*}{ Food $>$ non-food } & T2DM $>$ Healthy controls (fasted, placebo) & Amygdala & $\mathrm{L}$ & 13 & 2.79 & 0.02 & $-27,-4,-17$ \\
\hline & & Insula & $\mathrm{R}$ & 41 & 3.24 & 0.02 & $29,2,-14$ \\
\hline & & Insula & $\mathrm{L}$ & 13 & 2.99 & 0.04 & $-30,14,-17$ \\
\hline & & OFC & $\mathrm{R}$ & 61 & 3.77 & 0.004 & $39,26,-11$ \\
\hline \multirow[t]{2}{*}{ High-energy $>$ non-food } & & Insula & $\mathrm{L}$ & 19 & 3.21 & 0.02 & $-30,14,-14$ \\
\hline & & OFC & $\mathrm{R}$ & 16 & 2.87 & 0.05 & $42,29,-11$ \\
\hline Food $>$ non-food & Healthy controls > T2DM (postprandial, placebo) & - & - & - & - & - & - \\
\hline High-energy $>$ non-food & & - & - & - & - & - & - \\
\hline Food $>$ non-food & T2DM > Healthy controls (postprandial, placebo) & - & - & - & - & - & - \\
\hline High-energy $>$ non-food & & - & - & - & - & - & - \\
\hline \multicolumn{8}{|l|}{ Meal effects } \\
\hline Food $>$ non-food & Healthy controls: fasted $>$ postprandial (placebo) & Insula & $\mathrm{R}$ & 9 & 3.16 & 0.02 & $36,-16,7$ \\
\hline High-energy $>$ non-food & & Insula & $\mathrm{R}$ & 6 & 2.67 & 0.08 & $36,-16,7$ \\
\hline \multirow[t]{2}{*}{ Food $>$ non-food } & T2DM: fasted > postprandial (placebo) & Insula & $\mathrm{R}$ & 11 & 3.00 & 0.04 & $39,2,-14$ \\
\hline & & Insula & $\mathrm{L}$ & 24 & 2.85 & 0.05 & $-42,11,-8$ \\
\hline \multirow[t]{3}{*}{ High-energy $>$ non-food } & & Caudate nucl. & $\mathrm{L}$ & 38 & 3.58 & 0.007 & $-12,23,1$ \\
\hline & & Insula & $\mathrm{L}$ & 23 & 2.96 & 0.04 & $-36,8,-14$ \\
\hline & & OFC & $\mathrm{R}$ & 14 & 2.84 & 0.06 & $45,29,-14$ \\
\hline \multicolumn{8}{|c|}{ Effects of GLP-1 receptor blockade on meal effects } \\
\hline Food $>$ non-food & Healthy controls: meal reducing effects placebo $>$ ex9-39 & Insula & $\mathrm{R}$ & 33 & 2.70 & 0.08 & $36,-13,7$ \\
\hline High-energy $>$ non-food & & - & - & - & - & - & - \\
\hline \multirow[t]{2}{*}{ Food $>$ non-food } & T2DM: meal reducing effects placebo $>$ ex9-39 & Insula & $\mathrm{R}$ & 38 & 3.18 & 0.02 & $48,8,4$ \\
\hline & & Insula & $\mathrm{L}$ & 22 & 3.10 & 0.03 & $-27,26,1$ \\
\hline \multirow[t]{3}{*}{ High-energy $>$ non-food } & & OFC & $\mathrm{R}$ & 11 & 3.00 & 0.04 & $48,29,-11$ \\
\hline & & Caudate nucl. & $\mathrm{L}$ & 15 & 2.79 & 0.06 & $-12,23,1$ \\
\hline & & Insula & $\mathrm{L}$ & 16 & 2.69 & 0.08 & $-27,26,1$ \\
\hline
\end{tabular}

This table describes the areas where significant differences in CNS activations were observed for the three comparisons (group differences, effects of meal intake and effects of blockade of the GLP-1 receptor in both groups). For each comparison, the two contrasts (activation during food $>$ non-food pictures and high-energy food $>$ non-food pictures) are presented. The areas with significant differences are listed, including the cluster size of this effect, the $\mathrm{Z}$ value and the FWE corrected $p$ value after small volume correction. The last column describes the coordinates of the peak voxel of the observed difference in MNI space

Caudate nucl. caudate nucleus; ex9-39, exendin 9-39; FWE, family-wise error; L, left; MNI, Montreal Neurological Institute; R, right; T2DM, obese type 2 diabetes patients

and in the left insula $(p=0.04)$, left caudate nucleus $(p=0.007)$ and right OFC $(p=0.06)$ in response to viewing high-energy food pictures. The effect of meal intake was more pronounced in patients with diabetes compared with healthy lean individuals in the right insula $(p=0.008)$ and bilateral OFC (right $p=0.01$, left $p=0.03$ ) in response to food pictures.

Blockade of the GLP-1 receptor prevents effects of meal intake on CNS activation in response to food pictures In healthy lean individuals, the effect of GLP-1 receptor blockade tended to be statistically significant in the right insula
( $p=0.08$ ), indicating that the reducing effect of meal intake on CNS activation in response to viewing food pictures may have been blunted by GLP-1 receptor blockade. In obese patients with type 2 diabetes, however, the reducing effect of meal intake on CNS activation was largely prevented in the bilateral insula by GLP-1 receptor blockade in response to viewing food pictures (right $p=0.04$, left $p=0.03$ ). In addition, the reducing effect of meal intake on CNS activation was prevented by the GLP-1 receptor blockade in the right OFC $(p=0.04)$ and tended to be prevented in the left caudate nucleus $(p=0.06)$ and left insula $(p=0.08)$ in response to viewing high-energy food pictures (Fig. 4). 
Fig. 2 Between-group differences on CNS activation in response to viewing food pictures. (a) Axial and (b) coronal slices showing average

differences in activation in brain regions where patients with diabetes vs healthy lean individuals had hyperactivation in response to viewing food pictures. The colour scale reflects the T-value of functional activity. Results are presented at the threshold of $p<0.05$, FWE corrected on cluster extent. In the graphs, the BOLD signal intensity (effect size [AU]) for each group is plotted as mean and SEM for

(c) the right and (d) left insula, (e) right $\mathrm{OFC}$ and (f) left amygdala. AU, arbitrary units; FWE, family-wise error; HC, healthy lean controls/individuals; T2DM, type 2 diabetes patients
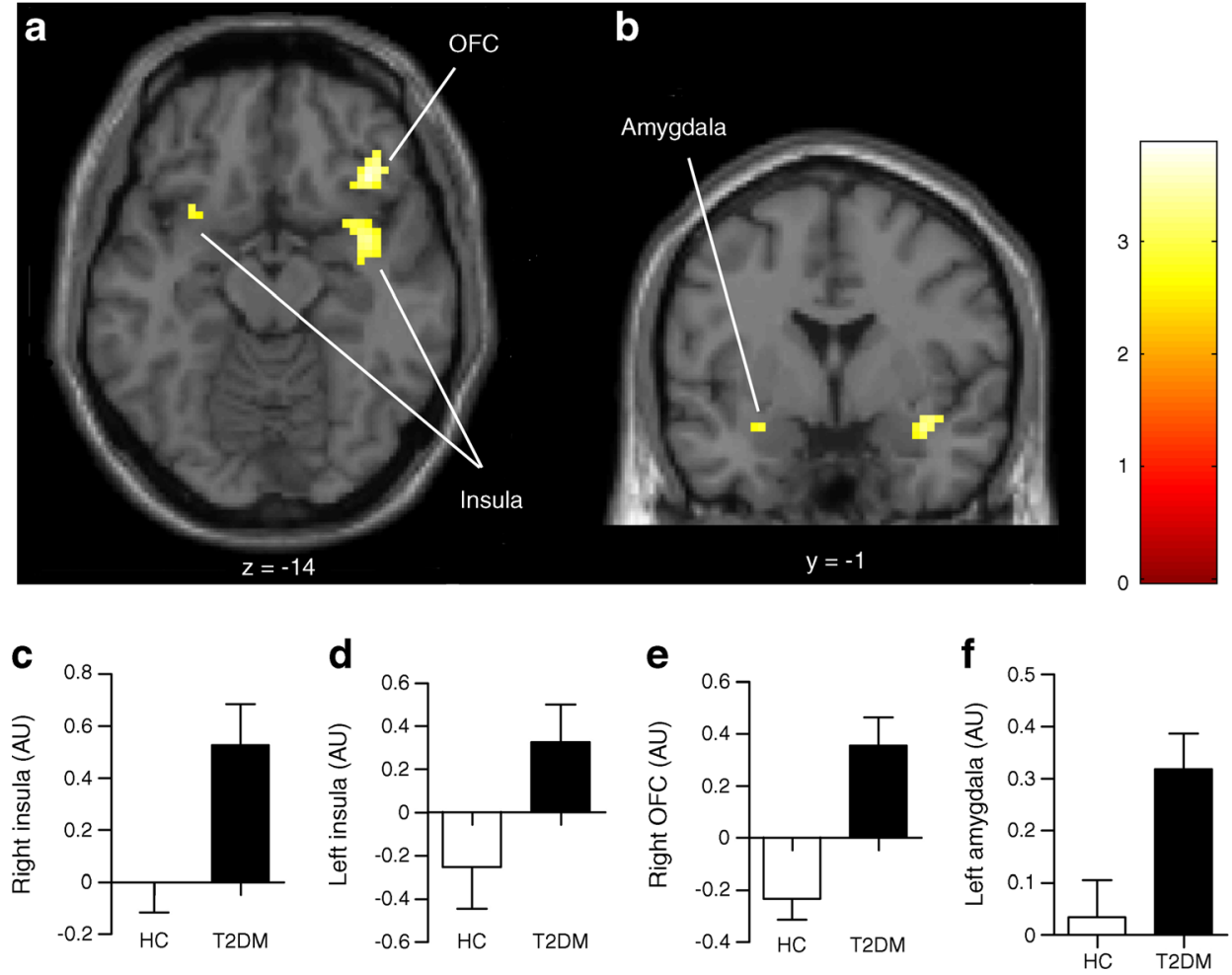
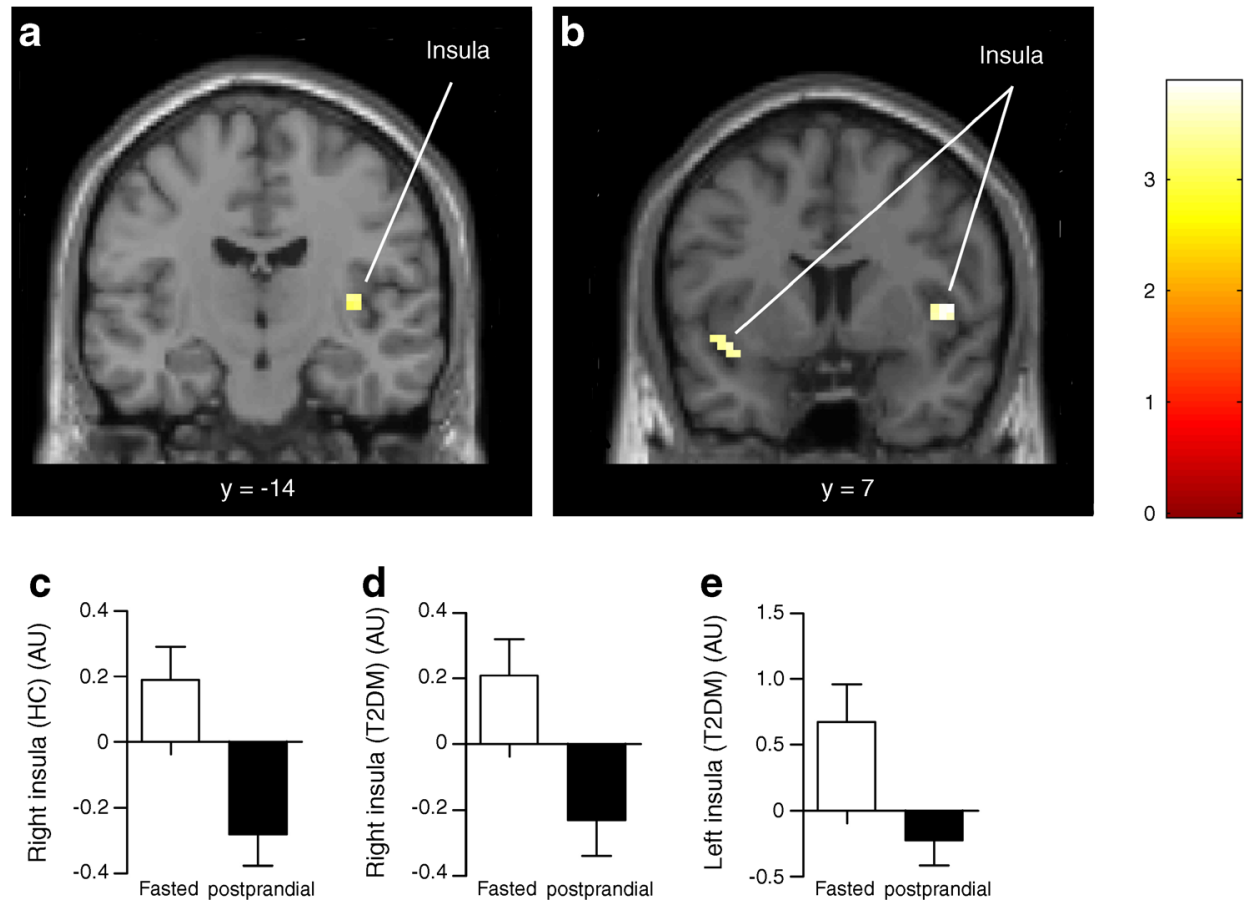

Fig. 3 Meal intake effects on CNS activation in response to viewing food pictures. Coronal slices showing areas where intake of the meal reduced activation in response to viewing food pictures $30 \mathrm{~min}$ after intake in (a) healthy lean individuals and (b) obese patients with diabetes. The colour scale reflects the T-value of functional activity. Results are presented at the threshold of $p<0.05$, FWE corrected on cluster extent. In the graphs,

the BOLD signal intensity (effect size [AU]) mean and SEM is plotted for healthy lean individuals in (c) the right insula and for patients with diabetes in (d) the right and (e) left insula. AU, arbitrary units; FWE, family-wise error; HC, healthy lean controls/individuals; T2DM, type 2 diabetes patients 
Appetite-related scores In the healthy lean group, no significant differences in postprandial changes in any of the appetite-related scores were observed between the two experimental days (data not shown). However, in the patients with diabetes, exendin 9-39 infusion prevented the postprandial reductions in the scores for hunger that were observed with placebo $60 \mathrm{~min}$ after meal intake (mean $\pm \mathrm{SEM}-2.3 \pm 0.7$ during placebo vs $-1.1 \pm 0.4$ during exendin $9-39 ; p=0.02$ ). This effect was not significant at $30 \mathrm{~min}$ after meal intake $(p=0.5)$. Postprandial changes in the other scores did not differ significantly between the infusions.

Blood glucose and plasma hormone levels Figure 5 shows the glucose and hormone responses during both test visits. Glucose levels were significantly higher in patients with type 2 diabetes compared with healthy lean individuals during both placebo and exendin 9-39 administration ( $p<0.001$ for both). Compared with placebo, exendin 9-39 had no effect on glucose levels in healthy lean individuals $(p=0.4)$, whereas in patients with diabetes, glucose levels were significantly higher throughout the test visit with exendin 9-39 compared with placebo $(p<0.001)$. There were no significant differences in GLP-1 levels between healthy lean individuals and patients with diabetes during placebo infusion $(p=0.2)$, but in both groups, GLP-1 levels were significantly higher during exendin 9-39 infusion ( $p=0.04$ and $p=0.002$ vs placebo in healthy lean individuals and patients with diabetes, respectively). Insulin levels did not differ between groups during placebo infusion $(p=0.3)$, and were unaffected by exendin 9-39 $(p=0.09$ and $p=0.4$ vs placebo in healthy lean individuals and patients with diabetes, respectively). During placebo infusion, glucagon levels were significantly higher in patients with diabetes compared with healthy lean individuals $(p=0.004)$, with levels being increased by exendin 9-39 compared with placebo $(p=0.004$ and $p<0.001$, respectively).

Adverse events Four individuals experienced abdominal discomfort $1-2 \mathrm{~h}$ after intake of the liquid meal $(n=2$ during both visits, $n=1$ during placebo and $n=1$ during exendin 9-39 administration). One individual vomited shortly after the intake of the liquid meal on the visit with exendin 9-39. One individual experienced dizziness after the first fMRI session with exendin 9-39 for approximately $10 \mathrm{~min}$.

\section{Discussion}

Using fMRI we observed that while viewing food pictures, obese patients with type 2 diabetes display hyperactivation in CNS areas involved in the regulation of food intake. Furthermore, meal intake reduced CNS activation in healthy lean individuals and in obese patients with type 2 diabetes, but this effect was more pronounced in patients with diabetes. We found that in patients with diabetes, the GLP-1 receptor antagonist exendin 9-39 significantly prevented the reducing effect of meal intake on CNS activation. This finding provides the first evidence in humans for an effect of endogenous GLP-1 on CNS activation in areas involved in the regulation of feeding, supporting the concept that GLP-1 has a physiological role in the central regulation of feeding.

Animal and human studies have demonstrated that administration of pharmacological amounts of GLP-1RA results in reduced appetite, food intake [4-7] and body weight [8], and these effects are at least partly mediated by effects on the CNS $[9-14,19]$. However, the physiological role of GLP-1 in the central regulation of feeding is less clearly established. Although not found consistently [25], treatment with the selective GLP-1 RA exendin 9-39 [17, 18, 26, 27] has resulted in significant increases in food intake [16]. In addition, in rats, central endogenous GLP-1 affects food intake and body weight $[11,18]$. In humans, the effects of endogenous GLP1 on prospective food consumption have been demonstrated [17], but changes in food intake could not be detected in a small pilot study [28]. Regarding the effects of endogenous GLP-1 on the CNS in humans, an association between postprandial increases in GLP-1 levels and the cerebral blood flow in areas involved in feeding behaviour has been observed [29], but our study is the first to investigate the effects of endogenous GLP-1 in an interventional setting.

In the current study, we showed that blockade of endogenous GLP-1 prevents the effects of meal intake on activation in the insula in response to the viewing of food pictures. The insula is known to be involved in the processing and evaluation of food cues and in craving for food [30,31]. Blocking the actions of endogenous GLP-1 during the viewing of highenergy pictures also affected activation in the OFC and caudate nucleus, which are known to be involved in the process of reward evaluation [32]. In line with this finding, studies in rodents suggest that GLP-1 may decrease the rewarding effect of food by acting on central reward circuits [33,34].

GLP-1 secreted from the intestine may access the brain through areas with a permeable blood-brain barrier. However, due to its short circulating half-life [35], it is likely that only a small amount of gut-derived endogenous GLP-1 reaches the brain. Therefore, it has been suggested that central effects of GLP-1 may also be mediated by indirect routes, such as vagal afferents originating from the intestine where GLP-1 levels are much higher [36]. In our study, we are not able to distinguish the direct from indirect effects.

The effects of endogenous GLP-1 on the CNS in our study might be explained by concomitant GLP-1 induced glucometabolic or hormonal changes. Glucose and glucagon have satiating effects that may be mediated by the CNS $[37,38]$. However, despite the higher glucose and glucagon levels, we observed higher activation in the patients with diabetes compared with healthy lean individuals and higher CNS 

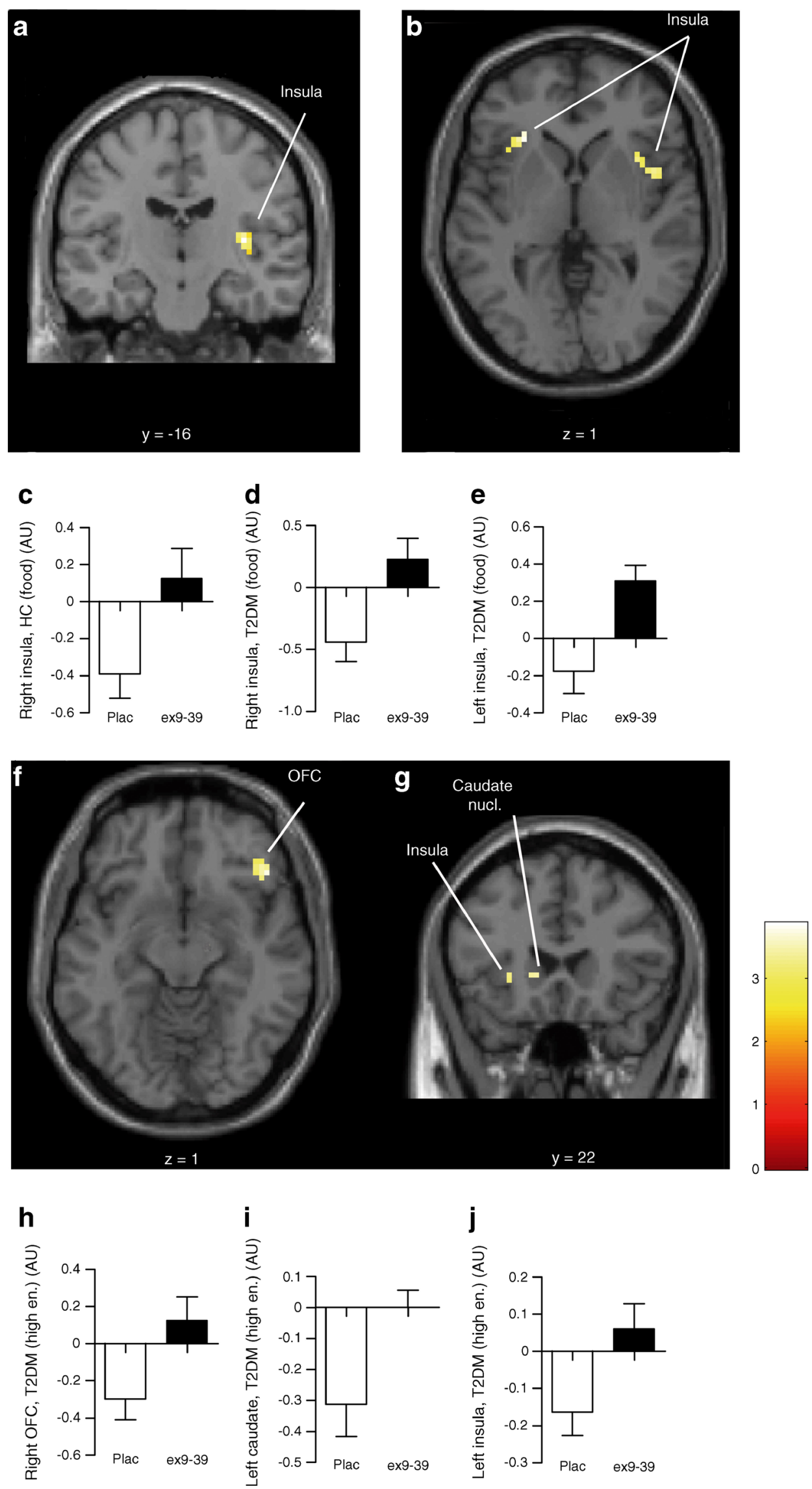
4 Fig. 4 Effects of GLP-1 receptor blockade on CNS responses. Axial and coronal slices showing average differences in activation in brain regions where blockade of endogenous GLP-1 effects with exendin 9-39 prevented reducing effects of meal intake on activation to viewing food pictures in (a) healthy lean individuals (right insula $p=0.08$ ) and (b) patients with type 2 diabetes (bilateral insula $p<0.05$ ). The colour scale reflects the T-value of functional activity. In the graphs, the BOLD signal intensity (effect size [AU]) mean and SEM for healthy lean individuals in (c) the right insula and in patients with diabetes in (d) the right and (e) left insula. The effect of exendin 9-39 in patients with diabetes in response to viewing high-energy food pictures is shown for (f) the right OFC $(p=0.04)$ and (g) left caudate nucleus $(p=0.06)$ and left insula $(p=0.08)$. In the graphs, the signal intensity is plotted for (h) the right OFC, (i) left caudate nucleus and (j) left insula. AU, arbitrary units; ex9-39, exendin 9-39; high en., high-energy food pictures; plac, placebo

activation following exendin 9-39 administration compared with placebo. Hence, differences in glucose and glucagon levels cannot explain our findings and neither can insulin levels, which did not differ between the groups nor between infusions. Despite higher GLP-1 levels during exendin 9-39 administration, we observed that exendin 9-39 blocked GLP-1 effects.

In the healthy lean individuals, we were not able to detect a significant effect of postprandial endogenous GLP-1 on activation in CNS reward and satiety circuits. Healthy lean individuals showed lower CNS activation during the presentation of food pictures, possibly reducing the power to detect alterations due to endogenous GLP-1. Similarly, in a previous study, we were able to detect effects of pharmacological levels
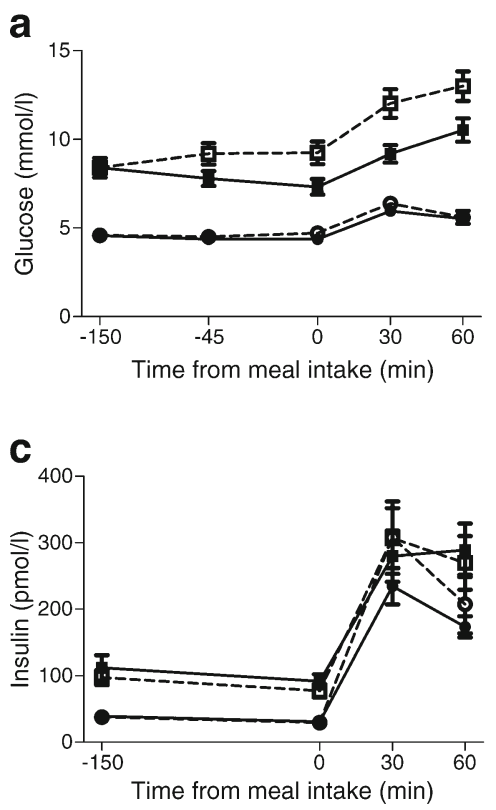

Fig. 5 Glucose and plasma hormone levels. Levels of (a) glucose, (b) total GLP-1, (c) insulin and (d) glucagon during placebo (black) and exendin 9-39 (white) infusion in healthy lean individuals (circles) and obese patients with diabetes (squares). Data are mean \pm SEM. Glucose levels were higher in diabetic patients vs healthy lean individuals $(p<0.001)$. Exendin 9-39 administration had no effect on glucose levels in healthy lean individuals $(p=0.4)$, but increased glucose levels in of GLP-1RA in healthy (normoglycaemic) obese individuals and obese patients with diabetes, whereas we [19] and others [39] were not able to detect these effects in healthy lean individuals. In accordance, the effect of meal intake on CNS activation in healthy lean individuals in the present study was much weaker than in patients with type 2 diabetes.

A limitation of this study is that we included only a group of healthy (normoglycaemic) lean individuals and obese patients with type 2 diabetes. We are, therefore, unable to distinguish the effects of obesity from diabetes per se. Although extrapolation of our findings in obese patients with diabetes to healthy (normoglycaemic) obese individuals awaits empirical confirmation, we believe that our findings may extend to healthy obese individuals for several reasons. First, in a previous study we showed that CNS activation in response to viewing food pictures was similarly increased in healthy obese individuals and in obese patients with type 2 diabetes [19]. Second, in this same study, we found that acute GLP-1RA administration reduced CNS activation in response to food pictures and reduced food intake in both healthy obese individuals and in obese patients with diabetes [19]. Third, several studies have shown that the effects of GLP-1RA treatment on body weight and food intake are similar in healthy obese individuals and in obese patients with diabetes $[8,40-43]$. Fourth, in accordance with the findings in our study in obese patients with type 2 diabetes, others observed that GLP-1 administration at physiological levels in healthy
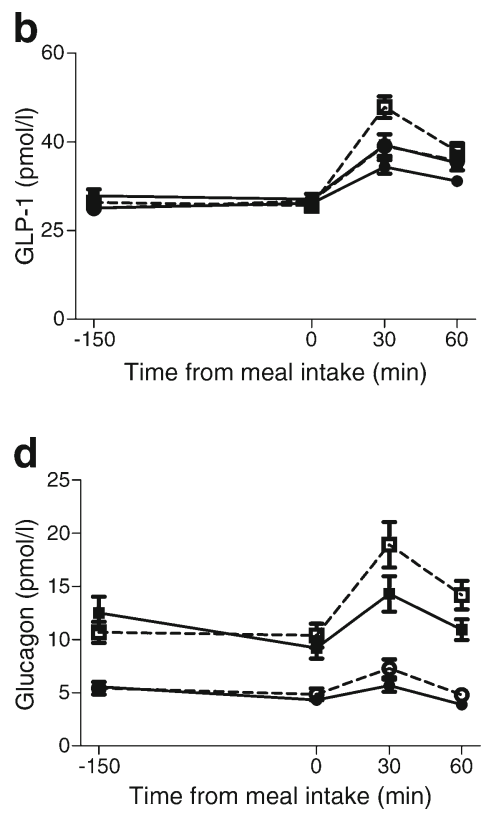

diabetic patients $(p=0.001)$. GLP-1 levels were higher during exendin 9-39 vs placebo administration (healthy, lean $p=0.04$; diabetes $p=$ 0.002 ). Insulin levels did not differ between groups nor between infusions in both groups $(p \geq 0.09)$. Glucagon levels were significantly higher in diabetic vs healthy lean individuals, and in both groups during exendin 9-39 vs placebo administration $(p \leq 0.004)$ 
obese men (without diabetes) resulted in decreased ratings of hunger and prospective food consumption [44]. Finally, in the present study, we demonstrated statistically significant effects of endogenous GLP-1 on CNS activation not only in obese patients with diabetes but also a trend in healthy lean individuals, suggesting that these effects are not confined to obese patients with diabetes.

Altered CNS activation after gastric distention has been described in obese patients [45], which may underlie their ability to consume large food volumes. However, in the current study, scanning was performed during rest only. Gastric distension may alter CNS baseline activity, but not necessarily activation differences when viewing food vs non-food pictures, as in the present study.

The reducing effect of GLP-1RA on gastric emptying is well-known [46, 47]. It could be speculated that a difference in the rate of gastric emptying between placebo and exendin 9-39 may have influenced our fMRI results. One study reported that exendin 9-39 has a small but significant effect on gastric emptying [48]. However, we performed the postprandial fMRI $30 \mathrm{~min}$ after meal intake, while the reported effect of exendin 9-39 on gastric emptying only started 45 min after intake [48]. In addition, others did not report altered gastric emptying by GLP-1 receptor blockade [49, 50].

In conclusion, our findings provide the first evidence that endogenous GLP-1 mediates satiating effects in areas of the CNS involved in satiety and reward in obese patients with type 2 diabetes. These data provide further insight into the central effects of peripheral signals, relaying information to the CNS and affecting feeding behaviour. Increased understanding of these processes may contribute to the development of new treatment strategies for obesity.

Acknowledgements We thank S. Gassman (Department of Internal Medicine, Diabetes Center, VU University Medical Center) and T. Schweigmann (Department of Radiology \& and Nuclear Medicine, VU University Medical Center) for their assistance during the test visits, as well as the individuals who participated in this study. We thank Nutricia for providing the Nutridrink.

Funding This work was supported in part by a grant from Novo Nordisk. RGIJ is financed by the Netherlands Organisation for Scientific Research (NWO) Innovational Research Incentives Scheme Veni (no. 91613082).

Duality of interest MD was consultant for Abbott, Astra Zeneca, Bristol-Myers Squibb (BMS), Boehringer Ingelheim, Eli Lilly, GI Dynamics, Inc., Merck Sharp \& Dohme (MSD), Novo Nordisk, Poxel Pharma and Sanofi, and speaker for BMS/Astra Zeneca, Eli Lilly, Novo Nordisk and Sanofi. Through MD, the VU University Medical Center received research grants from Abbott, BMS-Astra, Boehringer Ingelheim, Eli Lilly, Medtronic, MSD, Novo Nordisk and Sanofi. RGIJ is principal investigator of studies sponsored by research grants from Novo Nordisk and Eli Lilly. MD and RGIJ report receiving no personal payments in connection to the above mentioned activities, but all payments were directly transferred to the Diabetes Center non-profit Research Foundation. RJK and JHS are employees of Eli Lilly. CFD has received consultancy/ speaker fees from BMS, Boehringer Ingelheim, Lilly, Merck/MSD, Novartis and Novo Nordisk. JJH has received consultancy/speaker fees from Eli Lilly, Merck/MSD, and Novo Nordisk. All other authors declare that there is no duality of interest associated with their contribution to this manuscript.

Contribution statement JStK designed the study, conducted the experiments, designed the fMRI paradigm, performed data analysis and wrote the manuscript. DJV designed the fMRI paradigm, performed data analysis and wrote the manuscript. LvB designed the fMRI paradigm and contributed to writing the manuscript. FB performed analyses of all structural MRI scans and contributed to writing the manuscript. CFD, JJH, RJK and JHS performed laboratory analyses and contributed to writing the manuscript. MLD contributed to the design of the study and to writing the manuscript. MD designed the study. RGIJ designed the study, performed data analysis and wrote the manuscript. JStK and RGIJ are the guarantors of this work and, as such, had full access to all the study data and take responsibility for the integrity of the data and the accuracy of the data analysis. All authors other than MD have seen and approved the final version of the manuscript.

Open Access This article is distributed under the terms of the Creative Commons Attribution 4.0 International License (http:// creativecommons.org/licenses/by/4.0/), which permits unrestricted use, distribution, and reproduction in any medium, provided you give appropriate credit to the original author(s) and the source, provide a link to the Creative Commons license, and indicate if changes were made.

\section{References}

1. Morton GJ, Cummings DE, Baskin DG, Barsh GS, Schwartz MW (2006) Central nervous system control of food intake and body weight. Nature 443:289-295

2. Chaudhri OB, Wynne K, Bloom SR (2008) Can gut hormones control appetite and prevent obesity? Diabetes Care 31(Suppl 2): S284-S289

3. Kreymann B, Williams G, Ghatei MA, Bloom SR (1987) Glucagon-like peptide-1 7-36: a physiological incretin in man. Lancet 2:1300-1304

4. Flint A, Raben A, Astrup A, Holst JJ (1998) Glucagon-like peptide 1 promotes satiety and suppresses energy intake in humans. J Clin Invest 101:515-520

5. de Rodriquez FF, Navarro M, Alvarez E et al (2000) Peripheral versus central effects of glucagon-like peptide-1 receptor agonists on satiety and body weight loss in Zucker obese rats. Metabolism 49:709-717

6. Szayna M, Doyle ME, Betkey JA et al (2000) Exendin-4 decelerates food intake, weight gain, and fat deposition in Zucker rats. Endocrinology 141:1936-1941

7. Verdich C, Flint A, Gutzwiller JP et al (2001) A meta-analysis of the effect of glucagon-like peptide-1 (7-36) amide on ad libitum energy intake in humans. J Clin Endocrinol Metab 86:4382-4389

8. Vilsboll T, Christensen M, Junker AE, Knop FK, Gluud LL (2012) Effects of glucagon-like peptide-1 receptor agonists on weight loss: systematic review and meta-analyses of randomised controlled trials. BMJ 344:d7771

9. Shugrue PJ, Lane M, Merchenthaler I (1996) Glucagon-like peptide-1 receptor (GLP1-R) mRNA in the rat hypothalamus. Endocrinology 137:5159-5162

10. Turton MD, O'Shea D, Gunn I et al (1996) A role for glucagon-like peptide-1 in the central regulation of feeding. Nature 379:69-72

11. Meeran K, O'Shea D, Edwards CM et al (1999) Repeated intracerebroventricular administration of glucagon-like peptide-1-(7-36) 
amide or exendin-(9-39) alters body weight in the rat. Endocrinology 140:244-250

12. Merchenthaler I, Lane M, Shughrue P (1999) Distribution of pre-proglucagon and glucagon-like peptide-1 receptor messenger RNAs in the rat central nervous system. J Comp Neurol 403:261-280

13. Williams DL, Baskin DG, Schwartz MW (2009) Evidence that intestinal glucagon-like peptide-1 plays a physiological role in satiety. Endocrinology 150:1680-1687

14. Secher A, Jelsing J, Baquero AF et al (2014) The arcuate nucleus mediates GLP-1 receptor agonist liraglutide-dependent weight loss. J Clin Invest 124:4473-4488

15. Bloemendaal Lv, Ten Kulve JS, la Fleur SE, IJzerman RG, Diamant M (2014) Effects of GLP-1 on appetite and body weight: focus on the central nervous system. J Endocrinol 221:1-16

16. Patterson JT, Ottaway N, Gelfanov VM et al (2011) A novel human-based receptor antagonist of sustained action reveals body weight control by endogenous GLP-1. ACS Chem Biol 6:135-145

17. Steinert RE, Schirra J, Meyer-Gerspach AC et al (2014) Effect of glucagon-like peptide-1 receptor antagonism on appetite and food intake in healthy men. Am J Clin Nutr 100:514-523

18. Barrera JG, Jones KR, Herman JP, D'Alessio DA, Woods SC, Seeley RJ (2011) Hyperphagia and increased fat accumulation in two models of chronic CNS glucagon-like peptide-1 loss of function. J Neurosci 31:3904-3913

19. van Bloemendaal L, IJzerman RG, Ten Kulve JS et al (2014) GLP1 receptor activation modulates appetite- and reward-related brain areas in humans. Diabetes 63:4186-4196

20. Rothemund Y, Preuschhof C, Bohner G et al (2007) Differential activation of the dorsal striatum by high-calorie visual food stimuli in obese individuals. Neuroimage 37:410-421

21. Stoeckel LE, Weller RE, Cook EW III, Twieg DB, Knowlton RC, Cox JE (2008) Widespread reward-system activation in obese women in response to pictures of high-calorie foods. Neuroimage 41:636-647

22. LaBar KS, Gitelman DR, Parrish TB, Kim YH, Nobre AC, Mesulam MM (2001) Hunger selectively modulates corticolimbic activation to food stimuli in humans. Behav Neurosci 115:493-500

23. Orskov C, Rabenhoj L, Wettergren A, Kofod H, Holst JJ (1994) Tissue and plasma concentrations of amidated and glycineextended glucagon-like peptide I in humans. Diabetes 43:535-539

24. Sloan JH, Siegel RW, Ivanova-Cox YT, Watson DE, Deeg MA, Konrad RJ (2012) A novel high-sensitivity electrochemiluminescence (ECL) sandwich immunoassay for the specific quantitative measurement of plasma glucagon. Clin Biochem 45:1640-1644

25. Green BD, Irwin N, Gault VA, Bailey CJ, O'Harte FP, Flatt PR (2005) Chronic treatment with exendin(9-39)amide indicates a minor role for endogenous glucagon-like peptide-1 in metabolic abnormalities of obesity-related diabetes in ob/ob mice. J Endocrinol 185:307-317

26. Wang Z, Wang RM, Owji AA, Smith DM, Ghatei MA, Bloom SR (1995) Glucagon-like peptide-1 is a physiological incretin in rat. J Clin Invest 95:417-421

27. Schirra J, Sturm K, Leicht P, Arnold R, Goke B, Katschinski M (1998) Exendin(9-39)amide is an antagonist of glucagon-like peptide-1(7-36)amide in humans. J Clin Invest 101:1421-1430

28. Melhorn SJ, Tyagi V, Smeraglio A, Roth CL, Schur EA (2014) Initial evidence that GLP-1 receptor blockade fails to suppress postprandial satiety or promote food intake in humans. Appetite 82C:85-90

29. Pannacciulli N, Le DS, Salbe AD et al (2007) Postprandial glucagon-like peptide-1 (GLP-1) response is positively associated with changes in neuronal activity of brain areas implicated in satiety and food intake regulation in humans. Neuroimage 35:511-517

30. Small DM, Zatorre RJ, Dagher A, Evans AC, Jones-Gotman M (2001) Changes in brain activity related to eating chocolate: from pleasure to aversion. Brain 124:1720-1733
31. Pelchat ML, Johnson A, Chan R, Valdez J, Ragland JD (2004) Images of desire: food-craving activation during fMRI. Neuroimage 23:1486-1493

32. Hare TA, O'Doherty J, Camerer CF, Schultz W, Rangel A (2008) Dissociating the role of the orbitofrontal cortex and the striatum in the computation of goal values and prediction errors. J Neurosci 28: 5623-5630

33. Alhadeff AL, Rupprecht LE, Hayes MR (2012) GLP-1 neurons in the nucleus of the solitary tract project directly to the ventral tegmental area and nucleus accumbens to control for food intake. Endocrinology 153:647-658

34. Dickson SL, Shirazi RH, Hansson C, Bergquist F, Nissbrandt H, Skibicka KP (2012) The glucagon-like peptide 1 (GLP-1) analogue, exendin-4, decreases the rewarding value of food: a new role for mesolimbic GLP-1 receptors. J Neurosci 32:4812-4820

35. Vilsboll T, Agerso H, Krarup T, Holst JJ (2003) Similar elimination rates of glucagon-like peptide-1 in obese type 2 diabetic patients and healthy subjects. J Clin Endocrinol Metab 88:220-224

36. Plamboeck A, Veedfald S, Deacon CF et al (2013) The effect of exogenous GLP-1 on food intake is lost in male truncally vagotomized subjects with pyloroplasty. Am J Physiol Gastrointest Liver Physiol

37. Inokuchi A, Oomura Y, Nishimura H (1984) Effect of intracerebroventricularly infused glucagon on feeding behavior. Physiol Behav 33:397-400

38. Page KA, Seo D, Belfort-DeAguiar R et al (2011) Circulating glucose levels modulate neural control of desire for high-calorie foods in humans. J Clin Invest 121:4161-4169

39. DeSilva A, Salem V, Long CJ et al (2011) The gut hormones PYY 3-36 and GLP-1 7-36 amide reduce food intake and modulate brain activity in appetite centers in humans. Cell Metab 14:700-706

40. Gutzwiller JP, Drewe J, Goke B et al (1999) Glucagon-like peptide1 promotes satiety and reduces food intake in patients with diabetes mellitus type 2. Am J Physiol 276:R1541-R1544

41. Naslund E, Barkeling B, King N et al (1999) Energy intake and appetite are suppressed by glucagon-like peptide-1 (GLP-1) in obese men. Int J Obes Relat Metab Disord 23:304-311

42. Astrup A, Rossner S, Van GL et al (2009) Effects of liraglutide in the treatment of obesity: a randomised, double-blind, placebocontrolled study. Lancet 374:1606-1616

43. Rosenstock J, Klaff LJ, Schwartz S et al (2010) Effects of exenatide and lifestyle modification on body weight and glucose tolerance in obese subjects with and without pre-diabetes. Diabetes Care 33:1173-1175

44. Flint A, Raben A, Ersboll AK, Holst JJ, Astrup A (2001) The effect of physiological levels of glucagon-like peptide-1 on appetite, gastric emptying, energy and substrate metabolism in obesity. Int J Obes Relat Metab Disord 25:781-792

45. Tomasi D, Wang GJ, Wang R et al (2009) Association of body mass and brain activation during gastric distention: implications for obesity. PLoSOne 4:e6847

46. Nauck MA, Niedereichholz U, Ettler R et al (1997) Glucagon-like peptide 1 inhibition of gastric emptying outweighs its insulinotropic effects in healthy humans. Am J Physiol 273:E981-E988

47. Naslund E, Gutniak M, Skogar S, Rossner S, Hellstrom PM (1998) Glucagon-like peptide 1 increases the period of postprandial satiety and slows gastric emptying in obese men. Am J Clin Nutr 68:525-530

48. Deane AM, Nguyen NQ, Stevens JE et al (2010) Endogenous glucagon-like peptide-1 slows gastric emptying in healthy subjects, attenuating postprandial glycemia. J Clin Endocrinol Metab 95: 215-221

49. Salehi M, Vahl TP, D'Alessio DA (2008) Regulation of islet hormone release and gastric emptying by endogenous glucagon-like peptide 1 after glucose ingestion. J Clin Endocrinol Metab 93:4909-4916

50. Nicolaus M, Brodl J, Linke R, Woerle HJ, Goke B, Schirra J (2011) Endogenous GLP-1 regulates postprandial glycemia in humans: relative contributions of insulin, glucagon, and gastric emptying. J Clin Endocrinol Metab 96:229-236 